\title{
Extraction and Fractionation Effects on Antiplasmodial Activity and Phytochemical Composition of Palicourea hoffmannseggiana
}

\section{(ㄷ) (i) $($ 우 $\odot$}

Authors

Leticia Hiromi Ohashi ${ }^{1,2}$, Douglas Costa Gontijo², Maria Fernanda Alves do Nascimento², Luciano Ferreira Margalho3 ${ }^{3}$ Geraldo Célio Brandão ${ }^{4}$, Alaíde Braga de Oliveira1, 2

\section{Affiliations}

1 Programa de Pós-graduação em Ciências Farmacêuticas, Universidade Federal do Pará, Guamá, Belém, PA, Brazil

2 Departamento de Produtos Farmacêuticos, Faculdade de Farmácia, Universidade Federal de Minas Gerais, Pampulha, Belo Horizonte, MG, Brazil

3 Instituto Federal do Pará, Icuí-Guajará, Ananindeua, PA, Brazil

4 Escola de Farmácia, Universidade Federal de Ouro Preto, Ouro Preto, MG, Brazil

\section{Key words}

Palicourea hoffmannseggiana, Rubiaceae, monoterpene indole alkaloids, $\beta$-carboline alkaloids, Plasmodium

falciparum

received 18.10 .2020

revised 19.01.2021

accepted 25.01.2021

\section{Bibliography}

Planta Med Int Open 2021; 8: e34-e42

DOI 10.1055/a-1375-6456

ISSN 2509-9264

(C) 2021. The Author(s).

This is an open access article published by Thieme under the terms of the Creative Commons Attribution-NonDerivative-NonCommercial-License, permitting copying and reproduction so long as the original work is given appropriate credit. Contents may not be used for commercial purposes, or adapted, remixed, transformed or built upon. (https://creativecommons. org/licenses/by-nc-nd/4.0/)

Georg Thieme Verlag KG, Rüdigerstraße 14,

70469 Stuttgart, Germany

\section{Correspondence}

Alaíde Braga de Oliveira

Departamento de Produtos Farmacêuticos,

Faculdade de Farmácia, Universidade Federal de Minas Gerais, Av. Antônio Carlos, 6627, Pampulha CEP 31270-901

Belo Horizonte

MG

Brazil

Tel.: + 553134096950

alaidebragaoliveira@gmail.com
Supplementary Material is available under http://doi. org/ 1375-6456

\section{ABSTRACT}

The present study on Palicourea hoffmannseggiana, which was collected at Marapanim, state of Pará, Brazil, comprises the preparation of different stem and leaf extracts and fractions. Ethanol, hydroethanol, and water extracts were prepared by several methods and evaluated for in vitro activity against resistant Plasmodium falciparum (W2 strain), disclosing a low parasite growth inhibition effect $(<50 \%)$. Dereplication by UPLC-DAD-ESI ${ }^{-}$MS of the leaf ethanol extract showed the presence of two known alkaloids, lyalosidic and strictosidinic acids, along with a sinapoyl ester of lyalosidic acid, with $\mathrm{m} / \mathrm{z} 719.33$ $[\mathrm{M}+\mathrm{H}]^{+}$, which is possibly a new monoterpene indole alkaloid representative. Sequential liquid-liquid acid-base alkaloid separations from the leaf ethanol extract as well as directly from leaf powder afforded fractions of increased parasite growth inhibition, reaching up to $92.5 \pm 0.7 \%$. The most bioactive fractions were shown to contain the $\beta$-carboline alkaloids harmane and 4-methyl- $\beta$-carboline, along with $N$-methyl-tryptamine and $N$-acetyl-tryptamine, while monoterpene indole alkaloids were detected in inactive fractions of these processes. The present results demonstrate that these preliminary fractionation methods can lead to significantly active fractions supporting an adequate scale-up to carrying out the isolation of anti-plasmodial compounds. 


\section{Introduction}

Palicourea hoffmannseggiana (Schult.) Borhidi (Rubiaceae) is a recently accepted name of this specimen for which Psychotria hoffmannseggiana (Willd. ex Schult.) Müll. Arg. is a synonym according to Flora do Brasil 2020 [1]. On the other hand, different taxonomic data can be found in other open access databases such as The Plant List and TROPICOS. In the The Plant List database, P. hoffmannseggia$n a$ is pointed out as a synonym of $P$. hoffmannseggiana (Willd. Ex Schult.) Müll. Arg., which is the accepted name along with 20 more Psychotria names [2]. In TROPICOS, the accepted name is $P$. hoffmannseggiana (Roem. \& Schult.) Müll. Arg. along with P. hoffmannseggiana (Roem. \& Schult.) Borhidi [3]. This complex taxonomic situation is a consequence of the huge number of taxa in the Rubiaceae family that are distributed worldwide (13100), particularly in the Neotropics (5000) where they are present in most biomes. This family has the highest number of species in the order Gentianales, with about $66 \%$ of the species (about 115 genera and 1600 species) occurring in Brazil. However, considering that many species have not yet been collected in the country due to its vast unknown areas, especially in the Amazon Region and the Atlantic Forest, the number of species of this family might be up to 2000 [4].

Palicourea and Psychotria species are both known for the presence of alkaloids of high structural diversity, including those biosynthetically derived from tryptophan, such as monoterpene indole alkaloids (MIAs), $\beta$-carboline alkaloids, quinoline and isoquinoline alkaloids, and iridoids as well as other terpenoids, flavonoids, coumarins, and cyclic peptides (cyclotides). Some of these are responsible for a wide range of biological activities (cytotoxicity, analgesics, antivirals, antifungals, and modulators of the activity of the central nervous system) [5-7]. However, the number of MIAs and $\beta$-carboline alkaloids of known antimalarial/anti-plasmodial activity is relatively low. This fact motivated a systematic investigation of Palicourea and Psychotria taxa aiming to find potential antimalarial natural products [8]. In a recent review of the taxonomy, phytochemistry, biological activities, and antimalarial activity of $P$. hoffmannseggiana (Schult.) Borhidi, only psychorubrine, a quinone, from P. hoffmannseggiana Roem. \& Schult, and Psychotria barbiflora DC., as well as harmane from Psychotria rubra (not determined author) were recognized as showing moderate anti-plasmodial activity out of a total of 20 described natural products [8].

The impact of natural products in malaria chemotherapy is no doubt a valuable weapon to fight malaria. Malaria is still a global health problem and, according to the WHOs estimation, the number of cases worldwide were 251, 231, and 228 million in 2010, 2017 and 2018, respectively [9]. Overall, these data represent a significant decrease in the number of cases. However, in the Region of the Americas, an increase in cases, attributed to higher malaria transmission in Brazil, Nicaragua, and Venezuela, was recorded [9].

The development of new antimalarials is of great relevance due to the resistance of the malaria parasites to nearly all available antimalarial agents [10]. Therefore, the discovery of new antimalarial hits by investigation of plants of traditional use and those taxonomically related is still a valid strategy, particularly in Brazil, because of its rich biodiversity. Diverse strategies are available for the development of novel antimalarial drugs. The cellular screening for evaluation of antimalarial efficacy of pure compounds and extracts was generally carried out by the traditional radioisotopic assay using the tritiated hypoxanthine method ( ${ }^{3} \mathrm{H}$-hypoxanthine) to determine the level of Plasmodium falciparum growth inhibition (GI) [11]. Presently, the protocol most frequently used is a colorimetric enzymatic assay determined by an ELISA method based on the determination of the parasite lactate dehydrogenase $(P f L D H)$ for testing antimalarial drug susceptibility. It is cheap and requires minimum instrumentation. This method is also presently used on a large scale: in robotic equipment, high-throughput screening (HTS), in big pharma, and for screening millions of chemicals against multidrug-resistant $P$. falciparum $[12,13]$.

HTS, associated with artificial intelligence, is revolutionizing diverse areas of RD\&l, but not without the usual problems related to the acquisition and analyses of required data [14]. However, usually, academic researchers do not have access to these sophisticated HTS equipment. The usual bioguided fractionation of an active extract can be exploited with different strains of $P$. falciparum. When combined with powerful analytical methodologies, a rapid online identification of several known compounds is achieved. The profiling methods, employing spectroscopic methods in conjunction with chromatography, i. e., HPLC to DAD and MS (HPLC-DAD-ESI$\mathrm{MS}^{\mathrm{n}}$ ), are increasingly being used.

Against this backdrop, a bioguided screening of $P$. hoffmannseggiana (Schult.) Borhidi (Rubiaceae), a species with a complex taxonomic history, was extensively investigated with the aim of discovering antimalarial metabolites of minor content. Usual extracts, prepared by extractions with ethanol, ethanol/water, and hot water (tea), and preliminary fractionations by liquid-liquid partitions and alkaloid chemical separations were evaluated in vitro against the resistant $P$. falciparum $\mathrm{W} 2$ strain by the $P f L D H$ method. In addition, intense dereplication, based on tandem mass spectrometry (UPLCDAD-ESI-MS ${ }^{n}$ ) of different extracts and fractions, was also carried out. Further investigations on a preparative scale are expected to afford promising compounds.

\section{Results and Discussion}

The results of the in vitro antimalarial activity determination of different extracts and fractions of $P$. hoffmannseggiana leaves and stems are shown in $>$ Table $\mathbf{1}$ and are displayed in groups according to extraction procedures. Extracts of Group 1 included the use of different extractive liquids and procedures: 1 ) maceration of stems and leaves, separately, with ethanol; 2) sonication of stems and leaves with ethanol-water ( $7 / 3$ and $1 / 1)$ at room temperature; 3 ) decoction of stems and leaves with water. All these fractions showed a low percentage of parasite inhition $(\mathrm{Gl}<50 \%)$ and, therefore, were considered inactive. Indeed, no statistical difference was observed among the Group 1 extracts regardless of the plant part used, leaves or stems. In addition, a significant similarity was observed for the UPLC-DAD chromatogram profiles of these extracts, although greater intensity of some peaks was observed in the leaf extracts. Practically, no effect was noted in the antimalarial activity, as corroborated by the statistical data (Fig. 1S, Supplementary Material). These results are surprising since it is widely known that solvents and techniques used in extraction processes have been reported to influence the nature and quantity of secondary metabolites extracted [15]. Taken together, the selection of the best extraction method is of great relevance in chemical and biological in- 
- Table 1 Percentage of $P$. falciparum (W2) (PfLDH) growth inhibition of extracts and acid-base fractions of $P$. hoffmannseggiana.

\begin{tabular}{|c|c|c|}
\hline \multirow[t]{2}{*}{ Samples } & \multicolumn{2}{|c|}{ \% Growth inhibition } \\
\hline & {$[100.0 \mu \mathrm{g} / \mathrm{mL}]$} & {$[50.0 \mu \mathrm{g} / \mathrm{mL}]$} \\
\hline \multicolumn{3}{|l|}{${ }^{1}$ Group 1} \\
\hline 1.1Stems EtOH Ext. & $24.0 \pm 9.9^{A}$ & $24.0 \pm 9.9^{A}$ \\
\hline 1.2Stems EtOH/ $\mathrm{H}_{2} \mathrm{O} 7 / 3$ Ext. & $33.0 \pm 7.0^{\mathrm{A}}$ & $30.0 \pm 4.2^{\mathrm{A}}$ \\
\hline 1.2 Stems EtOH// $\mathrm{H}_{2} \mathrm{O} 1 / 1$ Ext. & $37.0 \pm 0.0^{\mathrm{A}}$ & $28.0 \pm 2.8^{\mathrm{A}}$ \\
\hline 1.3 Stems $\mathrm{H}_{2} \mathrm{O}$ Ext. & $39.5 \pm 0.7^{A}$ & $25.5 \pm 12.0^{\mathrm{A}}$ \\
\hline${ }^{1.1}$ Leaves EtOH Ext. & $26.0 \pm 4.2^{\mathrm{A}}$ & $25.0 \pm 5.6^{A}$ \\
\hline 1.2 Leaves EtOH/ $/ \mathrm{H}_{2} \mathrm{O} 7 / 3$ Ext. & $31.0 \pm 1.4^{\mathrm{A}}$ & $27.5 \pm 3.5^{\mathrm{A}}$ \\
\hline 1.2Leaves EtOH/ $/ \mathrm{H}_{2} \mathrm{O} 1 / 1$ Ext. & $37.0 \pm 7.0^{\mathrm{A}}$ & $35.5 \pm 6.3^{A}$ \\
\hline 1.3 Leaves $\mathrm{H}_{2} \mathrm{O}$ Ext. & $33.0 \pm 1.4^{\mathrm{A}}$ & $25.5 \pm 2.1^{\mathrm{A}}$ \\
\hline \multicolumn{3}{|l|}{${ }^{2}$ Group 2} \\
\hline Leaves EtOH Ext. & $26.0 \pm 4.2^{\mathrm{D}}$ & $25.0 \pm 5.6^{C}$ \\
\hline Leaves Acid $\mathrm{CHCl}_{3} \mathrm{Fr}$. & $80.0 \pm 8.4^{B}$ & $73.5 \pm 6.3^{A}$ \\
\hline Leaves Neutral $\mathrm{CHCl}_{3} \mathrm{Fr}$. & $78.5 \pm 2.1^{\mathrm{B}}$ & $76.5 \pm 0.7^{\mathrm{A}}$ \\
\hline Leaves Basic $\mathrm{CHCl}_{3} \mathrm{Fr}$. & $92.5 \pm 0.7^{A^{*}}$ & $67.0 \pm 1.4^{\mathrm{A}, \mathrm{B}}$ \\
\hline Leaves Basic EtOAc Fr. & $65.0 \pm 7.0^{c}$ & $24.5 \pm 7.7^{C}$ \\
\hline Leaves $n$-BuOH Fr. & $23.0 \pm 2.8^{\mathrm{D}}$ & $16.5 \pm 0.7^{C}$ \\
\hline \multicolumn{3}{|l|}{${ }^{3}$ Group 3} \\
\hline Stems EtOH Ext. & $24.0 \pm 9.9 c$ & $24.0 \pm 9.9^{B}, C$ \\
\hline Stems Basic DCM Fr. & $65.5 \pm 10.6^{\mathrm{A}}$ & $60.5 \pm 3.5^{\mathrm{A}}$ \\
\hline Stems n-BuOH Fr. & $52.5 \pm 2.1^{\mathrm{B}}$ & $37.5 \pm 2.1^{\mathrm{B}}$ \\
\hline Leaves EtOH Ext. & $26.0 \pm 4.2^{C}$ & $25.0 \pm 5.6^{c}$ \\
\hline Leaves Basic DCM Fr. & $64.0 \pm 1.4^{\mathrm{A}}$ & $59.5 \pm 4.9^{A}$ \\
\hline Leaves n-BuOH Fr. & $27.5 \pm 3.5^{c}$ & $25.0 \pm 1.4^{C}$ \\
\hline \multicolumn{3}{|l|}{ Positive Control } \\
\hline "Chloroquine diphosphate salt & $100.0 \pm 0.0^{*}$ & $100.0 \pm 0.0^{*}$ \\
\hline \multicolumn{3}{|c|}{$\begin{array}{l}\text { Note: Means ( } \pm \mathrm{SD}, \mathrm{n}=3 \text { ) followed by different letters were significantly } \\
\text { different within columns (Tukey test, } \alpha=0.05 \text { ). Statistical analyses of } \\
\text { parasitemia reduction at } 100.0 \text { and } 50.0 \mu \mathrm{m} / \mathrm{mL} \text { were performed } \\
\text { separately for each concentration as well as for each group } \\
\text { analyzed. "Statistical analysis of the anti-plasmodial activity of the } \\
\text { chloroquine control was performed separately with each sample and } \\
\text { concentration, and significant to } \mathrm{p}<0.05 \text {. Ext.: Extract; Fr.: fraction; } \\
\text { EtOH: ethanol; } \mathrm{H}_{2} \mathrm{O} \text { : water; } \mathrm{CHCl}_{3} \text { : chloroform; EtOAc: ethyl acetate; } \\
\mathrm{n} \text {-BuOH: butanol; DCM: dichloromethane. }{ }^{1.1} \text { Extraction by maceration; } \\
1.2 \text { extraction by sonication; }{ }^{1.3} \text { extraction by decoction; }{ }^{2} \text { fractionation by } \\
\text { acid base (acetic acid, Method A); }{ }^{3} \text { scid-base extraction (chloridric acid, } \\
\text { Method B). Conditions of extraction and fractionation: see Experimental } \\
\text { Section. A, B, and } \mathrm{C} \text { represent statistical differences between analysed } \\
\text { results, with no corresponding indicators. }\end{array}$} \\
\hline
\end{tabular}

vestigations [16]. Given the numerous taxonomic depictions for $P$. hoffmannseggiana and the various metabolites described, evaluation of the effects of different extractive methods on antimalarial activity is important, making viable use of more appropriate parts of the plants, solvents, isolation, and purification processes.

Taking into account that the various extracts showed phytochemical similarity, the characterization of the leaf ethanol extract by UPLC-ESI-MS², in the positive and negative ionization modes, presented here is closely related to the other extracts (Table 1S, Figs. 2S and 3S, Supplementary Material). Dereplication of extracts and fractions of $P$. hoffmannseggiana leaves and stems was carried out on the basis of UV absorption and typical fragmentation patterns by sequential MS analyses (UPLC-DAD-ESI-MS²) in comparison to literature data. Considerations on the main fragmentations registered by tandem mass spectrometry for the compounds detected in the $P$. hoffmannseggiana extracts are discussed here.

For three intense peaks in the total ion chromatogram in the negative mode ( $\mathrm{TIC} \mathrm{ESI}^{-}$) of $P$. hoffmannseggiana leaves ethanol extract (Fig. 3S, Supplementary Material), corresponding in the UPLCDAD chromatogram to peaks retention times (RT) 1.46, 1.82, and $1.95 \mathrm{~min}$, the same UV and MS data were observed: $\lambda_{\max } 217$, 280sh, 325 nm; m/z 353.09 [M - H] -(Fig. 3S, Supplementary Material). These data led to the identification of chlorogenic, neochlorogenic, and cryptochlorogenic acids, all of them showing fragmentation ions $\mathrm{m} / \mathrm{z} 191.40[\mathrm{M}-\mathrm{H}]^{-}$referring to quinic acid while $\mathrm{m} / \mathrm{z} 161.26[\mathrm{M}-\mathrm{H}]^{-}$is related to the caffeoyl residue ( $\mathbf{F i g} . \mathbf{1 a}$ ). Correlation of these isomeric chlorogenic acids with the registered observed RTs cannot be done due to their structural similarity. Three other intense peaks are shown in the UPLC-DAD chromatogram at RTs 2.67, 2.73, and 3.09 min. The first two were putatively identified as lyalosidic and strictosidinic acids, two known MIAs [17-19]. The first one, at RT 2.67 min, was identified as lyalosidic acid on the basis of the following UV and MS data (ESI ${ }^{+}$and $\left.\mathrm{ESI}^{-}\right)$: $\lambda_{\max } 217,303$, 350sh nm; $m / z 513.28[\mathrm{M}+\mathrm{H}]^{+}$and $m / z 511.38$ [M $-\mathrm{H}]^{-}$, respectively (Table 1S, Figs. $2 \mathrm{~S}$ and 3S, Supplementary Material). Indeed, the MS² data for the compound with an RT of 2.67 min is consistent with lyalosidic acid, with fragments corresponding to the loss of a glucose residue $m / z 351.38[\mathrm{M}+\mathrm{H}-162]^{+}$followed by the loss of $\mathrm{CO}_{2} \mathrm{~m} / \mathrm{z} 307.19[\mathrm{M}+\mathrm{H}-162-44]^{+}$, and $\mathrm{m} / \mathrm{z}$ $182.06[\mathrm{M}+\mathrm{H}-331]^{+}$, which can be attributed to the indole unity after the loss of the secologanin-glucose residue ( $>$ Fig. $\mathbf{1 b}$ ). The second MIA, at RT $2.73 \mathrm{~min}$, was attributed to the stereoisomer of strictosidinic acid: $\lambda_{\max } 221,300 \mathrm{sh}, 350 \mathrm{sh} \mathrm{nm} ; \mathrm{m} / \mathrm{z} 517.33$ $[\mathrm{M}+\mathrm{H}]^{+}$and $\mathrm{m} / \mathrm{z} 515.37[\mathrm{M}-\mathrm{H}]^{-}$(Table 1S, Figs. 2S and 3S, Supplementary Material). The similar fragmentations to the compound described above led to the loss of glucose $m / z 355.26[\mathrm{M}+\mathrm{H}-$ $162]^{+}$. A retro-Diels-Alder fragmentation of the secologanin moiety gave $\mathrm{m} / \mathrm{z} 284.94[\mathrm{M}+\mathrm{H}-232]^{+}$. The $\mathrm{m} / \mathrm{z} 187.20[\mathrm{M}+\mathrm{H}-$ $330]^{+}$must correspond to the indole unity after the loss of the secologanin-glucose moiety, besides $\mathrm{m} / \mathrm{z} 144.24$ corresponding to $\mathrm{C}_{10} \mathrm{H}_{10} \mathrm{~N}^{+}[\mathrm{M}+\mathrm{H}-373]^{+}$, which is probably derived by a heterocyclic ring fission (HRF) of the indole nucleus ( $\triangleright$ Fig. 1c). The presence of lyalosidic and strictosidinic acids or any isomer of those known as an MIA in different extracts of $P$. hoffmannseggiana leaves and stems is in accordance with literature data for several Palicourea species $[4,17,18]$. By contrast, the metabolite detected at RT 3.09 min is proposed to be a sinapoyl ester of lyalosidic acid, as inferred from the UV spectrum $\left(\lambda_{\max } 221,307,345 \mathrm{sh} \mathrm{nm}\right)$, the ESI ${ }^{+}$and ESI ${ }^{-}$ MS data $m / z 719.33[\mathrm{M}+\mathrm{H}]^{+}$and $m / z 717.44[\mathrm{M}-\mathrm{H}]^{-}$, as well as MS fragmentations pointing to the loss of a sinapoyl moiety to give $\mathrm{m} / \mathrm{z} 513.25[\mathrm{M}+\mathrm{H}-206]^{+}$along with the loss of a glucosylsinapoyl unity at $m / z 351.22[\mathrm{M}+\mathrm{H}-368]^{+}$for which $368=162$ (glucose residue) + 206 (sinapoyl residue), in addition to a diagnostic fragment for the sinapoyl acilium ion at $m / z 206.92[\mathrm{M}+\mathrm{H}-512]^{+} \mathrm{de}-$ rived by the loss of the lyalosidic acid residue itself ( $\triangleright$ Figs. $1 \mathrm{~d}$ and 2). Furthermore, the $\mathrm{MS}^{3}$ for the $\mathrm{m} / \mathrm{z} 206.92[\mathrm{M}+\mathrm{H}]^{+}$characteristic ions were observed for the sinapoyl residue at $m / z 191.67$ $[\mathrm{M}+\mathrm{H}-15]^{+}, \mathrm{m} / \mathrm{z} 175.84[\mathrm{M}+\mathrm{H}-31]^{+}$, and $\mathrm{m} / \mathrm{z} 145.48[\mathrm{M}+\mathrm{H}-$ $31-31]^{+}$, related to the losses of a methyl and methoxy radicals. 
a<smiles>O=C(O)[C@@]1(O)C[C@@H](O)[C@H](O)[C@H](O)[C@@H]1O</smiles>

$R_{1}=$ Caffeoyl, $R_{2}=R_{3}=H$ (Chlorogenic acid -354 Da)

$\mathrm{R}_{1}=\mathrm{R}_{3}=\mathrm{H}, \mathrm{R}_{2}=$ Caffeoyl (Criptochlorogenic acid - $354 \mathrm{Da}$ )

$R_{1}=R_{2}=H, R_{3}=$ Caffeoyl (Neochlorogenic acid - $354 \mathrm{Da}$ )

c

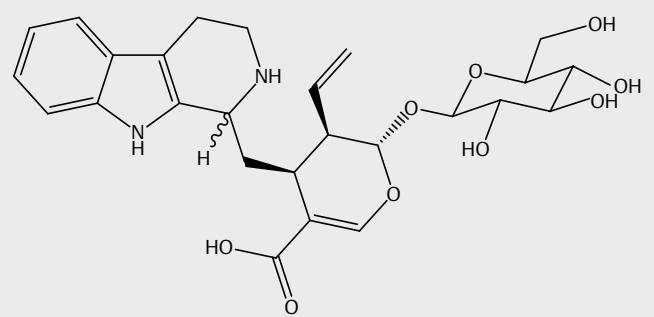

(epi) Strictosidinic acid (516 Da)

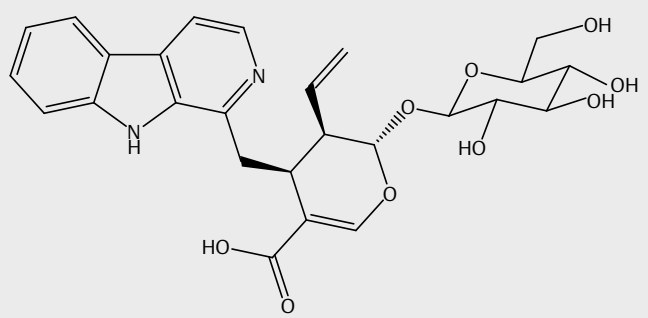

Lyalosidic acid (512 Da)

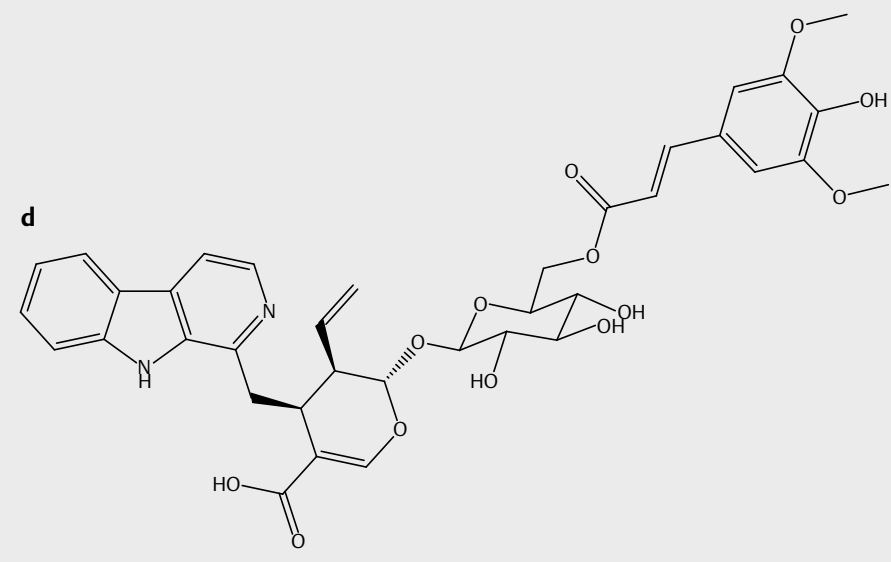

Sinapoyl-lyalosidic acid (718 Da)

Fig. 1 Chemical structures of the major compounds identified in the ethanol extract (Group 1) of P. hoffmannseggiana leaves by UPLC-DAD-ESI-MS².

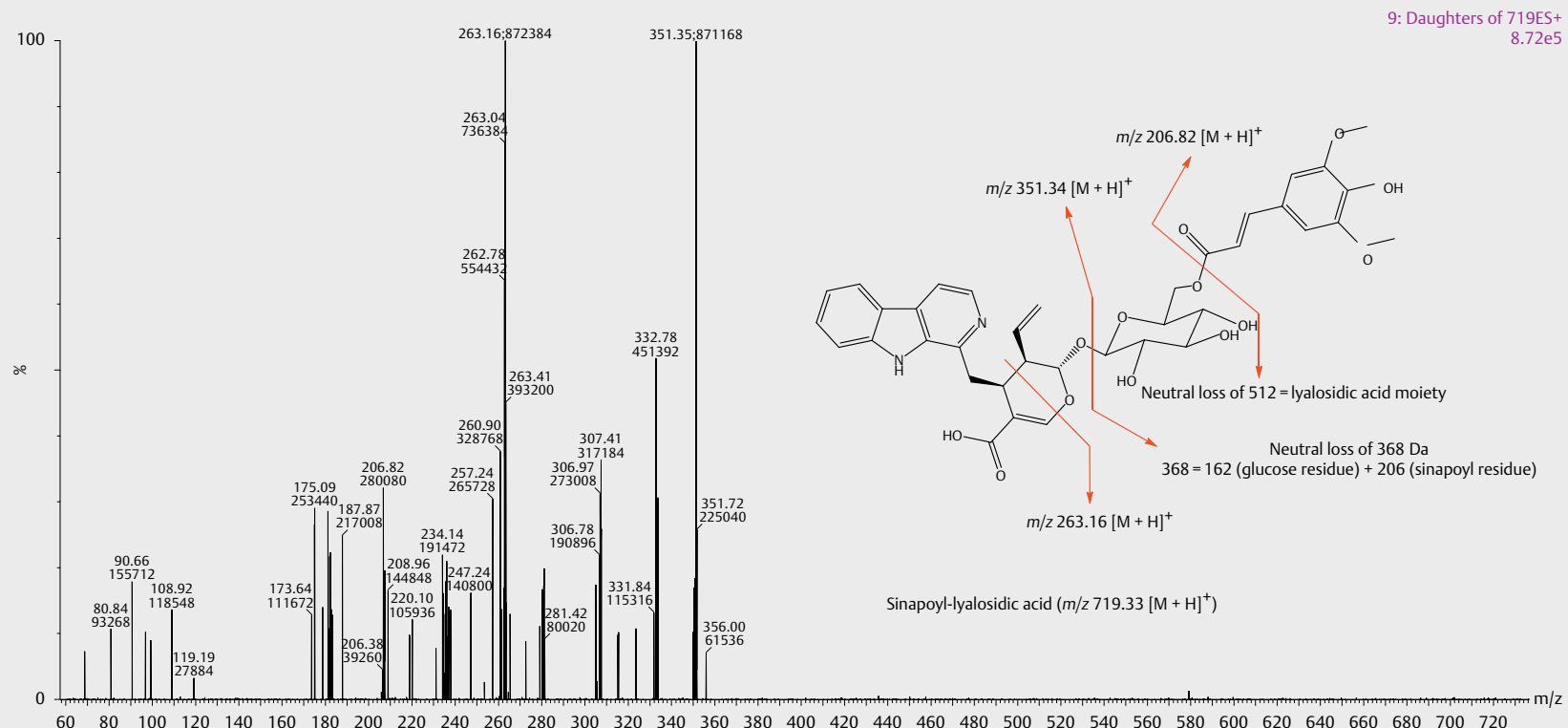

- Fig. $2 \mathrm{MS} / \mathrm{MS}$ spectrum and chemical structure (main fragmentations) of the sinapoyl-lyalosidic acid identified in the ethanol extract of $P$. hoffmannseggiana leaves by UPLC-DAD-ESI-MS². 
a

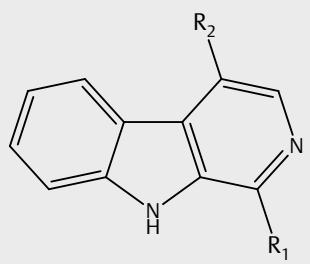

$\mathrm{R}_{1}=\mathrm{CH}_{3}, \mathrm{R}_{2}=\mathrm{H}$, 1-methyl- $\beta$-carboline (Harmane) (182 Da) $\mathrm{R}_{1}=\mathrm{H}, \mathrm{R}_{2}=\mathrm{CH}_{3}$, 4-methyl- $\beta$-carboline (182 Da) b

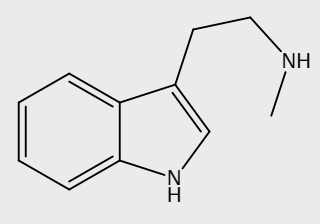

N-Methyltryptamine (174 Da) c

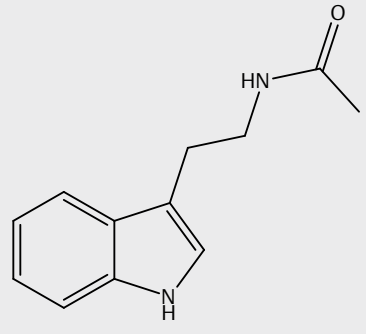

N-Acetyltryptamine (202 Da)

Fig. 3 Structures of the major compounds identified in the bioactive acid-base fractions (Group 2) of the P. hoffmannseggiana leaves by UPLCDAD-ESI-MS².

No reference was found for this putative alkaloid of MW 718 Da. Thus, this is possibly a new MIA, a sinapoyl-lyalosidic acid. Isolation and structural elucidation by NMR of this new MIA derivative to confirm the stereochemistry and localization of the sinapoyl moiety is ongoing. Similar MIA cinnamoyl-lyalosides (methyl esters of lyalosidic acid), such as (E)-O-6'-feruloyl-lyaloside and (E)-O-6'-sinapoyl-lyaloside, have already been detected in Palicourea and Psychotria species, while (E)-O-6'-sinapoyl-lyaloside was isolated from Palicourea adusta [17-20].

Because of the promising biological applications of alkaloids, there is continuous research for the development of new extraction and purification techniques of alkaloids [15]. Thus, a significant increase in the antimalarial activity was observed for Group 2 fractions ( $\triangleright$ Table 1 ) that were obtained after the fractionation of the leaf ethanol extract by acid-base separation of the alkaloids (Method A). In this procedure, only the Leaves $n$-BuOH Fr. (Fraction) was inactive $(\mathrm{Gl}<50 \%)$ and all other fractions showed moderate to high activity with a parasite $\mathrm{Gl}$ in the range of 65 to $92 \%$. Interestingly, differences in the UPLC-DAD and the full scan TIC profiles were observed for these fractions (Figs. 4S-6S, Supplementary Material). However, from a bioactive point of view, the antimalarial activities of the Group 2 fractions are very similar, except for the Leaves $n$-BuOH Fr. whose phytochemical profile and bioactivity are similar to the ethanol extract ( $\triangleright$ Table 1$)$.

The UPLC-DAD chromatograms of the five Group 2 bioactive acidbase fractions from $P$. hoffmannseggiana leaves are shown in Fig. 4S, Supplementary Material, and the RTs for the more prominent peaks along with their UV and MS data in positive and negative modes are discussed here (Table 1S, Figs. 5S and 6S, Supplementary Material). Attention is called to the UV spectra, which show characteristics of an indole nucleus, such as in tetrahydro- $\beta$-carbolines and tryptamines $\left(\lambda_{\max } 220,279 \mathrm{~nm}\right)$, as well as $\beta$-carboline alkaloids $\left(\lambda_{\max } 246\right.$, $299,365 \mathrm{~nm})[21,22]$. Identification of some constituents of this group is discussed in the following topics.

Leaves Neutral $\mathrm{CHCl}_{3}$ Fr. (Table 1S, Figs. 4SC, 5SB, and 6SB, Supplementary Material): RT $2.40 \mathrm{~min} ; \lambda_{\max } 246,299,365 \mathrm{~nm} ; \mathrm{m} / \mathrm{z}$ $183.10[\mathrm{M}+\mathrm{H}]^{+}$and $\mathrm{m} / \mathrm{z} 180.88[\mathrm{M}-\mathrm{H}]^{-}$.

The UV spectrum for this metabolite is indicative of a $\beta$-carboline. A methyl- $\beta$-carboline compound was inferred from the protonated molecular ion $\mathrm{m} / \mathrm{z} 183.10[\mathrm{M}-\mathrm{H}]^{-}$, and by the following fragment ions at $\mathrm{m} / \mathrm{z} 115.05[\mathrm{M}+\mathrm{H}-68]^{+}$derived from the $\beta$-carboline nucleus by an $\mathrm{HRF}$ radical loss of $\mathrm{C}_{3} \mathrm{H}_{4} \mathrm{~N}_{2} \cdot$. However, the broad peak at RT 2.40 might be related to the coelution of isomeric compounds with $\mathrm{m} / \mathrm{z} 183.10[\mathrm{M}+\mathrm{H}]^{+}$(Fig. 4S, Supplementary Material). Indeed, three natural methyl- $\beta$-carbolines supporting a methyl group in the 1, 2, or 4 position are known ( $\vee$ Fig. 3a) [23] and the present data do not allow to make a distinction for two out of the three possible constitutional isomers. The presence of the deprotonated molecular ion $\mathrm{m} / \mathrm{z} 180.88[\mathrm{M}-\mathrm{H}]^{-}$supports the exclusion of 2-methyl$\beta$-carboline as one of the three possible isomers, since this isomer would not show significant negative ionization because of the $\mathrm{NH}$ bond absence.

Leaves Basic $\mathrm{CHCl}_{3}$ Fr. (Table 1S, Figs. 4SD, 5SC, and 6SC, Supplementary Material): RT $1.83 \mathrm{~min} ; \lambda_{\max } 220,279$ nm; m/z 174.61 $[\mathrm{M}+\mathrm{H}]^{+}$.

This peak was already attributed here to $N$-methyl-tryptamine $\left(\mathrm{m} / \mathrm{z} 174.61[\mathrm{M}+\mathrm{H}]^{+}\right)$and fragment ions of $\mathrm{m} / \mathrm{z} 115.09[\mathrm{M}+\mathrm{H}-$ $60]^{+}$for the loss of $\mathrm{C}_{3} \mathrm{H}_{10} \mathrm{~N} \bullet, \mathrm{m} / \mathrm{z} 143.05[\mathrm{M}+\mathrm{H}-32]^{+}$due to the loss of $\mathrm{CH}_{6} \mathrm{~N} \bullet, \mathrm{m} / \mathrm{z} 91.17$ corresponding to $[\mathrm{M}+\mathrm{H}-84]^{+}$derived from the loss of $\mathrm{C}_{5} \mathrm{H}_{10} \mathrm{~N} \bullet$, and $\mathrm{m} / \mathrm{z} 77.25[\mathrm{M}+\mathrm{H}-98]^{+}$related to different HRF fragmentations of the indole nucleus ( $\mathbf{F i g} \mathbf{3 b}$ ) [24, 25].

Leaves Basic $\mathrm{CHCl}_{3}$ Fr. (Table 1S, Figs. 4SC, 5SC, and 6SC, Supplementary Material): RT $2.64 \mathrm{~min} ; \lambda_{\max } 246,299,365 \mathrm{~nm} ; \mathrm{m} / \mathrm{z}$ $183.10[\mathrm{M}+\mathrm{H}]^{+}$and $\mathrm{m} / \mathrm{z} 180.88[\mathrm{M}-\mathrm{H}]^{-}$.

Identification of the metabolite at RT $2.64 \mathrm{~min}(\mathrm{~m} / \mathrm{z} 183.10$ $[\mathrm{M}+\mathrm{H}]^{+}$) was discussed above in the analysis of the Leaves Neutral $\mathrm{CHCl} 3 \mathrm{Fr}$. (item a) on the basis of the fragment ion at $\mathrm{m} / \mathrm{z} 141.24$ $[\mathrm{M}+\mathrm{H}-42]^{+}$resulting from the loss of $\mathrm{C}_{2} \mathrm{H}_{4} \mathrm{~N} \cdot$ that was taken as an indication of the localization of the methyl group at $\mathrm{C}-1$, corresponding, therefore, to the known harmane ( $\mathbf{F i g . 3 a ) . ~ O t h e r ~ f r a g - ~}$ ments such as $m / z 167.80[\mathrm{M}+\mathrm{H}-15]^{+}, \mathrm{m} / z 115.05[\mathrm{M}+\mathrm{H}-68]^{+}$, $m / z 88.99[\mathrm{M}+\mathrm{H}-94]^{+}$, and $m / z 65.07[\mathrm{M}+\mathrm{H}-118]^{+}$are also in accordance for typical $\beta$-carbolines [26].

Leaves Basic $\mathrm{CHCl}_{3}$ Fr. (Table 1S, Figs. 4SC, 5SC, and 6SC, Supplementary Material): RT $3.85 \mathrm{~min} ; \lambda_{\max } 220,279 \mathrm{~nm} ; \mathrm{m} / \mathrm{z} 203.23$ $[\mathrm{M}+\mathrm{H}]^{+}$and $\mathrm{m} / \mathrm{z} 201.33[\mathrm{M}-\mathrm{H}]^{-}$.

The RT at 3.85 min was attributed to $N$-acetyl-tryptamine $(\mathrm{m} / \mathrm{z}$ $\left.203.23[\mathrm{M}+\mathrm{H}]^{+}\right)$, characterized by the fragment ions at $\mathrm{m} / \mathrm{z} 159.84$ 
$[\mathrm{M}+\mathrm{H}-43]^{+}$for the loss of an acetyl moiety and $\mathrm{m} / \mathrm{z} 143.97[\mathrm{M}+\mathrm{H}$ -59] ${ }^{+}$due to the loss of the radical $\mathrm{CH}_{3} \mathrm{COHN} \bullet$ ( $\vee$ Fig. $3 \mathrm{c}$ ).

Peaks of lower intensity in the UPLC-DAD chromatograms of the Group 2 fractions of $P$. hoffmannseggiana leaves extract (Fig. 4S, Supplementary Material), disclosing similar UV spectra, were observed in other bioactive fractions, and some of them clearly overlap to major peaks identified in the leaf ethanol extract as discussed in the last part. Furthermore, some $\beta$-carboline alkaloids such as harmine and harmaline showed moderate in vitro anti-plasmodial activity ( $\mathrm{IC}_{50} 8.0$ and $25.1 \mu \mathrm{g} / \mathrm{mL}$, respectively) against $P$. falciparum[27]. Harmane and related analogues were also isolated from Guiera senegalensis (Combretaceae), a plant from Mali, with traditional use for malaria treatment that afforded harmane and tetrahydroharmane with significant antimalarial activity $\left(\mathrm{IC}_{50}<4 \mu \mathrm{g} /\right.$ $\mathrm{mL})[28,29]$. These simple $\beta$-carboline alkaloids were also found in South American plants such as Banisteriopsis caapi (Malpighiaceae) and Psychotria viridis (Rubiaceae), which are key ingredients in the hallucinogenic beverage Ayahuasca, used by Amazonian indigenous people and found in other Psychotria and Palicourea species (Rubiaceae) [22]. In addition, a wide review on antimalarial activity of natural $\beta$-carboline alkaloids against different $P$. falciparum strains, including simple diversifications of the basic tricyclic structure, initially reported on their potent cytotoxicity and potential antimalarial activity [30]. However, as far as we are concerned, there is no report on the antimalarial/antimalarial activity of simple $\beta$-carbolines and tryptamines from $P$. hoffmannseggiana (Schult.) Borhidi and its synonyms [7, 8]. The described results stimulated to carry on the classical acid-base separation procedure of alkaloids, starting by the extraction of $P$. hoffmannseggiana leaf and stem powders with $1 \mathrm{~N} \mathrm{HCl}$ (Method B) as shown in Group 3 ( Table 1). Stems and Leaves Basic DCM Frs. were moderately active $(\mathrm{Gl} \sim 64 \%)$ and disclosed statistical similarity data in both assayed concentrations (Group 3) ( $\triangleright$ Table 1). The Stems $n$-BuOH Fr. showed low parasite $\mathrm{Gl}(52.5 \pm 2.1 \mu \mathrm{g} / \mathrm{mL}$, at $100.0 \mu \mathrm{g} / \mathrm{mL})$ and the Leaves $n$-BuOH Fr. was inactive $(\mathrm{Gl}<50 \%)$ in both concentrations. Therefore, the Leaves and Stems Basic DCM Frs. of this process were about three times more active in relation to the respective ethanol extracts. However, Group 3 fractions disclosed significantly lower activity than Group 2 ( $\triangleright$ Table 1 ). Marked distinctions in the UPLCDAD and TIC profiles of Group 2 and Group 3 fractions might therefore be related to different active compounds in these fractions that disclosed different ranges of the parasite GI (Figs. 7S-10S, Supplementary Material).

Phytochemically, the Leaves and Stems DCM Frs. showed weak peaks in the UPLC-DAD chromatograms that were not identified (Figs. 7S and 8S, Supplementary Material). On the other hand, the positive TIC of the Leaves and Stems Basic DCM for the major constituents disclosed pairs of peaks differing by $44 \mathrm{Da}$ (Table $1 \mathrm{~S}$ and Fig. 9S, Supplementary Material), similar to the observed profiles of the ethanol extracts of Palicourea sessilis leaves and stems, in which hydroxycinnamic acid amides derived from $p$-coumaric, caffeic, and/or ferulic acids with amines such as putrescine, agmatine, and/or spermine were identified for the first time as major components of a Palicourea species (Figs. 9S and 10S, Supplementary Material). However, they are of greater molecular masses than the ones described for $P$. sessilis [31] and were not yet identified. In addition, despite TIC chromatograms profiles of the Group 3 fractions being significantly different from Group 2, the presence of a peak at $\mathrm{m} / \mathrm{z} 183.10[\mathrm{M}+\mathrm{H}]^{+}$relative to methyl- $\beta$-carbolines ( $\mathbf{F i g} . \mathbf{3 a}$ ) was also observed in the leaves and stems of Group 3 basic DCM fractions. Thus, here these compounds could also be associated with the moderate antiplasmodial activity of these fractions.

Taken together, these results show that the increase in the polarity of the extractive solvents $\left(\mathrm{EtOH} \rightarrow \mathrm{EtOH} / \mathrm{H}_{2} \mathrm{O} 7 / 3 \rightarrow \mathrm{EtOH} / \mathrm{H}_{2} \mathrm{O}\right.$ $1 / 1 \rightarrow \mathrm{H}_{2} \mathrm{O}$ ) as well as the different extractive methods (maceration, sonication, and decoction) did not have a significant change on the antiplasmodial activity of Group 1 extracts ( $>$ Table 1 ). However, a significant increase in the antiplasmodial activity of fractions obtained from the leaf ethanol extract fractionation of $P$. hoffmannseggiana was observed, as can be seen by comparing the results for Groups 1 and 2 ( Table 1). Furthermore, the chlorogenic acid isomers as well as the MIA presently identified in the leaf ethanol extract were not detected in the bioactive fractions of $P$. hoffmannseggiana leaves and stems. These compounds are responsible for the major peaks in the $n$-BuOH fractions (Groups 2 and 3), which did not show antiplasmodial activity (parasite $\mathrm{Gl}<50 \%$ ) ( $\triangleright$ Table 1 and Figs. 4S and 7S, Supplementary Material). Thus, one might infer that lyalosidic acid and its sinapoyl derivative as well as strictosidinic acid and the chlorogenic acid isomers might not possess relevant antiplasmodial action.

Traditionally, alkaloid extraction is usually performed by acidbase liquid-liquid procedures starting with methanol or ethanol extracts, or even directly from the powdered plant material, followed by alkalinization and extraction with solvents of increasing polarity. Sequential variation of both the strength of the base as well as the polarity of the extractive solvents can led to special alkaloid separations [16]. Variations in this process are necessary given the diversity of alkaloids and the complexity of samples, especially for the discovery of minor and structurally similar compounds [32]. Indeed, the fractionation aiming at obtaining alkaloid-rich fractions allowed the detection of $\beta$-carboline alkaloids that were not detected in the different crude extracts containing MIAs as major components. Besides, significant variations were observed in the phytochemical composition between fractions originating from different fractionation procedures.

In conclusion, the LC-MS analyses of extracts and fractions obtained from $P$. hoffmannseggiana by acid-base extractions and liquid-liquid partitions bioguided by in vitro antiplasmodial activity allowed for the identification of major compounds occurring in this species as well as to infer those that may be potentially related to the observed bioactivity. In this sense, the extracts and fractions containing mostly MIAs disclosed low antiplasmodial activity. On the other hand, fractions containing mostly $\beta$-carboline alkaloids and tryptamine derivatives disclosed significant activity that was previously demonstrated for harmane, presently detected in this Palicourea species. In addition, phytochemical reports on several plants of synonyms attributed to this accepted name supports our assumption that several metabolites described for these plants might be found in a further analysis of the complex chromatographic profile of this species. Furthermore, the present screening, which was guided by in vitro antiplasmodial bioassays and LC-MS analyses, has demonstrated that preliminary fractionations of inactive crude extracts are recommended in order not to neglect the presence of minor active compounds. Scale-up of the processes 
here described with $P$. hoffmannseggiana will certainly afford promising active fractions of interest for phytomedicine development and/or isolation of new antimalarial hits.

\section{Materials and Methods}

\section{Plant material}

Aerial parts of $P$. hoffmannseggiana were collected at Crispin beach in the municipality of Marapanin, state of Pará (S $0^{\circ} 35^{\prime} 35.23$ ” W 470 39' 28.92"), an area of a restinga ecosystem (sandbank vegetation). The plant was taxonomically identified by Dr. L. F. Margalho, Instituto Federal do Pará, Belém, Brazil. A voucher specimen was deposited at the Herbarium of Museu Paraense Emílio Goeldi under the code MG 226057.

\section{Preparation of ethanol, hydroethanol, and aqueous extracts of Palicourea hoffmannseggiana stems and leaves}

After drying in a circulating air oven at $37^{\circ} \mathrm{C}$, the dried leaves and stems were milled, and the powder was kept in dark flasks. The different extracts were prepared as follows (Fig. 11S, Supplementary Material): 1) Preparation of ethanol extracts: powdered leaves (200 $\mathrm{g})$ and stems (500 g) were submitted to maceration with ethanol $(96 \mathrm{GL}$ ) for 6 days (plant:solvent ratio, 1:20 w/v). Subsequently, the extractive solutions were concentrated in a rotary evaporator affording the dry ethanol extract of the leaves (Leaves EtOH Ext., $16 \mathrm{~g}$ ) and ethanol extract of the stems (Stems EtOH Ext., $13 \mathrm{~g}$ ), which were kept in a desiccator under vacuum. 2) Preparation of hydroethanol extracts: powdered leaves $(10 \mathrm{~g})$ and stems $(10 \mathrm{~g})$ in two proportions (7/3 and 1/1, plant:solvent ratio, 1:20 w/v) were obtained by sonication for $5 \mathrm{~min}$ at room temperature. The extractive solutions were concentrated in a rotary evaporator and subsequently in a freeze dryer affording the dry hydroethanol extracts of the leaves (Leaves EtOH/ $\mathrm{H}_{2} \mathrm{O}$ 7/3 Ext. $0.5 \mathrm{~g}$; Leaves EtOH/ $\mathrm{H}_{2} \mathrm{O}$ $1 / 1 \mathrm{Ext} .0 .8 \mathrm{~g}$ ) and hydroethanol extracts of the stems (Stems EtOH/ $\mathrm{H}_{2} \mathrm{O} 7 / 3$ Ext. $0.4 \mathrm{~g}$; Stems EtOH/ $\mathrm{H}_{2} \mathrm{O} 1 / 1$ Ext. $0.5 \mathrm{~g}$ ), which were kept in a desiccator under vacuum. 3) Preparation of aqueous extracts: powdered leaves $(10 \mathrm{~g})$ and stems $(10 \mathrm{~g})$ were prepared by decoction with distilled water at $90^{\circ} \mathrm{C}$ (plant:solvent ratio, 1:20 w/v) for $10 \mathrm{~min}$. The extractive solutions were concentrated in a freeze dryer affording the dry aqueous extract of the leaves (Leaves $\mathrm{H}_{2} \mathrm{O}$ Ext. $0.8 \mathrm{~g}$ ), and aqueous extract of the stems (Stems $\mathrm{H}_{2} \mathrm{O}$ Ext. 0.45 $\mathrm{g})$, which were kept in a desiccator under vacuum.

\section{Fractionation of Palicourea hoffmannseggiana ethanol leaves extract by acid-base procedure (Method A)}

To an aliquot of Leaves EtOH Ext. (10 g), an aqueous solution of $10 \%$ acetic acid $(\mathrm{v} / \mathrm{v}) \mathrm{pH} 1-2(100 \mathrm{~mL})$ was added, and the mixture was kept under sonication for $40 \mathrm{~min}$. Subsequently, the acidic aqueous layer was separated by filtration following extraction with chloroform $(4 \times 50 \mathrm{~mL})$. The combined chloroform phases were dried (anhydrous $\mathrm{Na}_{2} \mathrm{SO}_{4}$ ) and after concentration, gave the leaves an acid chloroform fraction (Leaves Acid $\mathrm{CHCl}_{3}$ Fr., $200 \mathrm{mg}$ ). Afterwards, the acidic aqueous layer was neutralized with conc. $\mathrm{NH}_{4} \mathrm{OH}$ to $\mathrm{pH} 7$ and was then extracted with chloroform $(4 \times 50 \mathrm{~mL})$, gi- ving the leaves a neutral chloroform fraction (Leaves Neutral $\mathrm{CHCl}_{3}$ Fr., $31 \mathrm{mg}$ ). Finally, conc. $\mathrm{NH}_{4} \mathrm{OH}$ was added to the neutral phase to $\mathrm{pH}$ 9-10 and was then sequentially extracted with chloroform, ethyl acetate, and $n$-butanol ( $4 \times 50 \mathrm{~mL}$ each solvent), giving the following fractions, leaves basic chloroform fraction (Leaves Basic $\mathrm{CHCl}_{3} \mathrm{Fr}$., $16 \mathrm{mg}$ ), leaves basic ethyl acetate fraction (Leaves Basic EtOAc Fr., $76 \mathrm{mg}$ ), and leaves $n$-butanol fraction (Leaves $n$-BuOH Fr., $1.3 \mathrm{~g}$ ), respectively (Fig. 12S, Supplementary Material).

\section{Acid-base extraction of Palicourea hoffmannseggiana stems and leaves (Method B)}

Aliquots of stem and leaf powders ( $10 \mathrm{~g}$ each) were separately submitted to maceration with $50 \mathrm{~mL}$ of aqueous solution of $1 \mathrm{~N} \mathrm{HCl}$ $(3 \times 50 \mathrm{~mL})$, and the acidic aqueous layers were extracted with $n$ hexane $(2 \times 100 \mathrm{~mL})$, giving the respective $n$-hexane fractions that were not assayed due to their low quantities $(<2 \mathrm{mg}$ ). Subsequently, the acidic aqueous layers were alkalinized with conc. $\mathrm{NH}_{4} \mathrm{OH}$ to $\mathrm{pH} 9-10$, and then the basic aqueous phases were extracted with dichloromethane $(2 \times 100 \mathrm{~mL})$, giving the stems dichloromethane fraction (Stems DCM Fr., $85 \mathrm{mg}$ ) and the leaves dichloromethane fraction of (Leaves DCM Fr., $90 \mathrm{mg}$ ). Finally, the basic aqueous phases (pH 9-10) were extracted with $n$-butanol $(2 \times 100 \mathrm{~mL})$, giving the stems $n$-butanol fraction (Stems $n$-BuOH Fr., $11 \mathrm{mg}$ ) and the leaves $n$-butanol fraction (Leaves, $n$-BuOH Fr., 30 mg) (Fig. 13S, Supplementary Material).

\section{Chemical analysis}

\section{UPLC-DAD}

Analyses were performed using an ACQUITY UPLC H-Class Core System (Waters) with an ACQUITY UPLC PDA Detector, according to Gontijo et al. [33], in the Faculdade de Farmácia, UFMG, equipped with a reversed-phase column ACQUITY UPLC BEH $(1.7 \mu \mathrm{m}$, $50 \times 2 \mathrm{~mm}$ i.d.; Waters). The mobile phase consisted of water $0.1 \%$ formic acid (solvent $A$ ) and acetonitrile $0.1 \%$ formic acid (solvent B). The elution protocol was 0-13 min, linear gradient from 5 to $95 \% \mathrm{~B}$. The flow rate was $0.3 \mathrm{~mL} \mathrm{~min}^{-1}$, and the sample injection volume was $4.0 \mu \mathrm{L}$. The UV spectra were registered from 200 to $400 \mathrm{~nm}$.

\section{Mass spectrometry analysis}

Mass spectrometry analysis by electron spray ionization (ESI-MS) was performed in an UPLC Acquity (Waters) equipped with a tandem triple quadrupole detector (TQqQD). The ESI source was operated in the following conditions: positive and negative ion modes; ion spray voltage $-4 \mathrm{kV}$; orifice voltage $-60 \mathrm{~V}$, with helium as the collision gas; collision energy was set at $30 \mathrm{eV}$; capillary voltage $3500 \mathrm{~V}$; capillary temperature $320^{\circ} \mathrm{C}$; source voltage $5 \mathrm{kV}$; vaporizer temperature $320^{\circ} \mathrm{C}$; corona needle current $5 \mathrm{~mA}$; and sheath gas, nitrogen 27 psi. Analyses were run in the full scan mode (100-2000 Da). Data acquisition was achieved with MassLynx V4. 1 software (Waters).

\section{Antiplasmodial assay}

Evaluation of the in vitro anti-plasmodial activity against chloroquine-resistant $P$. falciparum (W2 strain) was carried out for two concentrations (100 and $50 \mu \mathrm{g} / \mathrm{mL}$ ) of the different extracts and fractions by the quantification of the $P f L D H$ according to methodology routinely performed in our laboratory at the Faculdade de Farmá- 
cia, UFMG [17, 34]. Chloroquine diphosphate salt ( $\geq 98.5 \%$ purity; Sigma-Aldrich) was the standard antimalarial drug.

\section{Statistical analysis}

All data are expressed as means \pm standard deviations of triplicate measurements. Antiplasmodial activity was determined for two concentrations $(100$ and $50 \mu \mathrm{g} / \mathrm{mL}$ ) of the different extracts and fractions and the results were submitted to ANOVA and Tukey tests. All statistical analyses were performed using the software SigmaPlot 12.5 with $\alpha=0.05$ [35].

\section{Acknowledgments}

To Coordenação de Aperfeiçoamento de Pessoal de Nível Superior - CAPES for a master's scholarship to L. H. O. and a postdoctoral fellowship to D. C. G. and to Conselho Nacional de Desenvolvimento Científico e Tecnológico - CNPq for a senior research fellowship to A. B. O.

\section{Conflict of Interest}

The authors declare that they have no conflict of interest.

\section{References}

[1] Flora do Brasil. Available at http://floradobrasil.jbrj.gov.br/reflora/ floradobrasil/FB609534. Accessed December 1, 2020

[2] Borhidi A. Transfer of the Mexican species of Psychotria subgen. Heteropsychotria to Palicourea based on morphological and molecular evidences. Acta Bot Hung 2011; 53: 245-250

[3] Tropicos. Available at: http://www.tropicos.org/Name/100408987. Accessed December 1, 2020

[4] Delprete PG, Jardim JG. Systematics, taxonomy and floristics of Brazilian Rubiaceae: An overview about the current status and future challenges. Rodriguésia 2012; 63: 121-128

[5] Martins D, Nunez CV. Secondary metabolites from Rubiaceae species. Molecules 2015; 20: 13422-13495

[6] Berger A, Tanuhadi E, Brecker L, Schinnerl J, Valant-Vetschera K. Chemodiversity of tryptamine-derived alkaloids in six Costa Rican Palicourea species (Rubiaceae - Palicoureeae). Phytochemistry 2017; 143: $124-131$

[7] Calixto N, Pinto M, Ramalho S, Burguer M, Bobey A, Zoung M, Bolzani V, Pinto A. The genus Psychotria: phytochemistry, chemotaxonomy, ethnopharmacology and biological properties. J Braz Chem Soc 2016; 27: $1355-1378$

[8] Ohashi LH, Oliveira AB. Palicourea hoffmannseggiana (Schult.) Borhidi (Rubiaceae): a revision on botanical taxonomy, phytochemistry, biological activities and antimalarial activity. Elec J Collect Health 2020; 43: e3027

[9] World Health Organization. World Malaria Report. Available at: https:// www.who.int/news-room/feature-stories/detail/world-malaria-report-2019. Accessed May 29, 2020

[10] World Health Organization. World Malaria Report. Available at: https:// www.who.int/publications/i/item/9789240012813. Accessed December 23, 2020

[11] Maji AK. Drug susceptibility testing methods of antimalarial agents. Trop Parasitol 2018; 8: 70-76
[12] Baniecki ML, Wirth DF, Clardy ]. High-throughput Plasmodium falciparum growth assay for malaria drug discovery. Antimicrob Agents Chemother 2007; 51: 716-723

[13] Fidock DA, Rosenthal PJ, Croft SL, Brun R, Nwaka S. Antimalarial drug discovery: Efficacy models for compound screening. Nat Rev Drug Discov 2004; 3: 509-520

[14] Merk D, Friedrich L, Grisoni F, Schneider G. De Novo Design of bioactive small molecules by artificial intelligence. Mol Inform 2018; 37: 1700153

[15] Dirar Al, Alsaadi DHM, Wada M, Mohamed MA, Watanabe T, Devkota $\mathrm{PH}$. Effects of extraction solvents on total phenolic and flavonoid contents and biological activities of extracts from Sudanese medicinal plants. South African J Bot 2019; 120: 261-267

[16] Belwal T, Ezzat SM, Rastrelli L, Bhatt ID, Daglia M, Baldi A, Devkota HP, Orhan IE, Patra JK, Das G. A critical analysis of extraction techniques used for botanicals: Trends, priorities, industrial uses and optimization strategies. Trends Anal Chem 2018; 100: 82-102

[17] Gontijo DC, Leite JPV, Nascimento MFA, Brandão GC, Oliveira AB. Bioprospection for antiplasmodial activity, and identification of bioactive metabolites of native plants species from the Mata Atlântica biome, Brazil. Nat Prod Res, Advance online publication 24 June. 2019; doi: 10.1080/14786419.2019.1633645

[18] Berger A, Kostyan MK, Klose SI, Gastegger M, Lorbeer E, Brecker L, Schinnerl J. Loganin and secologanin derived tryptamine-iridoid alkaloids from Palicourea crocea and Palicourea padifolia (Rubiaceae). Phytochemistry 2015; 116: 162-169

[19] Klein-Junior L, Cretton S, Allard P, Genta-Jouve G, Passos C, Salton J, Bertelli P, Pupier M, Jeannerat D, Vander Y, Gasper A, Wolfender J, Christen P, Henriques A. Targeted isolation of monoterpene indole alkaloids from Palicourea sessilis. J Nat Prod 2017; 80: 3032-3037

[20] Valverde ], Tamayo G, Hesse M. $\beta$-Carboline monoterpenoid glucosides from Palicourea adusta. Phytochemistry 1999; 52: 1485-1489

[21] Sangster AW, Stuart KL. Ultraviolet spectra of alkaloids. Chem Rev 1964; 65: 69-130

[22] Wang YH, Samoylenko V, Tekwani BL, Khan IA, Miller LS, Chaurasiya ND, Rahman MM, Tripathi L, Khan SI, Joshi VC, Wigger FT. Muhammad I. Composition, standardization and chemical profiling of Banisteriopsis caapi, a plant for the treatment of neurodegenerative disorders relevant to Parkinson's disease. J Ethnopharmacol 2010; 128 : 662-671

[23] Shi Y, Wang R, Zhu X, Xu D, Liu W, Feng F. A self-feedback network based on liquid chromatography-quadrupole-time of flight mass spectrometry for system identification of $\beta$-carboline alkaloids in Picrasma quassioides. Sci Rep 2017; 7: 713841

[24] Chen BH, Liu JT, Chen WX, Chen HM, Lin CH. A general approach to the screening and confirmation of tryptamines and phenethylamines by mass spectral fragmentation. Talanta 2008; 74: 512-517

[25] Ouyang Y, Liang Y, Li S, Luo X, Zhang L, Tang Z, Wang Q, Xu X. Interpretation of the characteristic fragmentation mechanism through determining the initial ionization site by natural spin density: A study on the derivatives of tryptophan and tryptamine. Int J Mass Spectrom 2009; 286: 112-121

[26] Li S, Liu W, Teng L, Cheng X, Wang Z, Wang C. Metabolites identification of harmane in vitro/in vivo in rats by ultra-performance liquid chromatography combined with electrospray ionization quadrupole time-of-flight tandem mass spectrometry. J Pharm Biomed Anal 2014; 91: 53-62

[27] Astulla A, Zaima K, Matsuno Y, Hirasawa Y, Ekasari W, Widyawaruyanti A, Zaini NC, Morita H. Alkaloids from the seeds of Peganum harmala showing antiplasmodial and vasorelaxant activities. J Nat Med 2008; 62: $470-472$ 
[28] Ancolio C, Azas N, Mahiou V, Ollivier E, Di Giorgio C, Keita A, Timon-David P, Balansard G. Antimalarial activity of extracts and alkaloids isolated from six plants used in traditional medicine in Mali and Sao Tome. Phytother Res 2002; 16: 646-649

[29] Fiot J, Sanon S, Azas N, Mahiou V, Jansen O, Angenot L, Ollivier E. Phytochemical and pharmacological study of roots and leaves of Guiera senegalensis J.F. Gmel (Combretaceae). J Ethnopharmacol 2006; 106: $173-178$

[30] Ashok P, Ganguly S, Murugesan S. Review on in-vitro anti-malarial activity of natural $\beta$-carboline alkaloids. Mini-Rev Med Chem 2013; 13 : 1778-1791

[31] Samulski GB, Gontijo DC, Moreira NC, Brandão GC, Oliveira AB. Dereplication of Palicourea sessilis ethanol extracts by UPLC-DAD-ESIMS/MS discloses the presence of hydroxycinnamic acid amides and the absence of monoterpene indole alkaloids. Biochem Syst Ecol 2020; 92: 104114
[32] Wei X, Shen H, Wang L, Meng Q, Liu W. Analyses of Total Alkaloid Extract of Corydalis yanhusuo by Comprehensive RP $\times$ RP Liquid Chromatography with pH Difference. J Anal Methods Chem 2016; 2016: 9752735

[33] Gontijo DC, Brandão GC, Gontijo PC, Oliveira AB, Diaz MAN, Fietto LG, Leite JPV. Identification of phenolics compounds and biologically related activities from Ocotea odorifera aqueous extract leaves. Food Chem 2017; 230: 618-626

[34] Gontijo DC, Brandão GC, Nascimento MFA, Oliveira AB. Antiplasmodial activity and cytotoxicity, isolation of active alkaloids, and dereplication of Xylopia sericea leaves ethanol extract by UPLC-DAD-ESI-MS/MS. J Pharm Pharmacol 2019; 71: 260-269

[35] Systat Software. https:||systatsoftware.com| 